\title{
Is the school food environment conducive to healthy eating in poorly resourced South African schools?
}

\author{
Mieke Faber ${ }^{1, *}$, Sunette Laurie ${ }^{2}$, Mamokhele Maduna $^{3}$, Thokozile Magudulela ${ }^{3}$ and \\ Ellen Muehlhoff ${ }^{4}$ \\ ${ }^{1}$ Nutritional Intervention Research Unit, Medical Research Council, PO Box 19070, Tygerberg 7505, \\ South Africa: ${ }^{2}$ Agricultural Research Council - Roodeplaat Vegetable and Ornamental Plant Institute, Pretoria, \\ South Africa: ${ }^{3}$ Department of Basic Education, National School Nutrition Programme Directorate (Sustainable \\ Food Production in Schools (SFPS) and Nutrition Education), Pretoria, South Africa: ${ }^{4}$ Nutrition Education and \\ Consumer Awareness Group, Nutrition Division, Food and Agriculture Organization, Rome, Italy
}

Submitted 9 January 2013: Final revision received 1 June 2013: Accepted 25 July 2013: First published online 4 September 2013

\begin{abstract}
Objective: To assess the school food environment in terms of breakfast consumption, school meals, learners' lunch box, school vending and classroom activities related to nutrition.

Design: Cross-sectional survey.

Setting: Ninety purposively selected poorly resourced schools in South Africa.

Subjects: Questionnaires were completed by school principals ( $n$ 85), school feeding coordinators ( $n$ 77), food handlers ( $n$ 84), educators ( $n$ 687), randomly selected grade 5 to 7 learners $(n$ 2547) and a convenience sample of parents ( $n$ 731). The school menu ( $n 75)$, meal served on the survey day, and foods at tuck shops and food vendors ( $n$ 74) were recorded.

Results: Twenty-two per cent of learners had not eaten breakfast; $24 \%$ brought a lunch box, mostly with bread. Vegetables (61\%) were more often on the school menu than fruit (28\%) and were served in $41 \%$ of schools on the survey day compared with $4 \%$ serving fruit. Fifty-seven per cent of learners brought money to school. Parents advised learners to buy fruit (37\%) and healthy foods (23\%). Tuck shops and vendors sold mostly unhealthy foods. Lack of money/poverty (74\%) and high food prices (68\%) were major challenges for healthy eating. Most (83\%) educators showed interest in nutrition, but only $15 \%$ had received training in nutrition. Eighty-one per cent of educators taught nutrition as part of school subjects. Conclusions: The school food environment has large scope for improvement towards promoting healthy eating. This includes increasing access to vegetables and fruit, encouraging learners to carry a healthy lunch box, and regulating foods sold through tuck shops and food vendors.
\end{abstract}

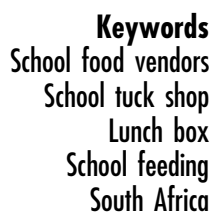

South Africa experiences the double burden of undernutrition and overweight. A national survey showed that $20.7 \%$ of 1 - to 9 -year-old children were stunted, $8 \cdot 1 \%$ were underweight, $5 \cdot 8 \%$ were wasted, and $14 \cdot 0 \%$ were either overweight or obese ${ }^{(1)}$. Overweight/obesity increases progressively as children become older ${ }^{(2)}$, and the second national youth risk behaviour survey showed that $20 \%$ of secondary-school learners were overweight and 5\% were obese $^{(3)}$. Overweight/obesity is even more prevalent during adulthood and, in $2003,54.9 \%$ of adult women and $29.8 \%$ of adult men were either overweight or obese ${ }^{(4)}$.

The majority of the South African population consumes a predominantly cereal-based diet, with a low intake of foods of animal origin, vegetables and fruit ${ }^{(5)}$. The diet has little variety $^{(6,7)}$ and is deficient in many of the key micronutrients ${ }^{(5)}$. Vitamin A-rich vegetables and fruit are the most neglected foods ${ }^{(6)}$. There are indications that food insecurity has decreased over the past 10 years, yet a substantial proportion of the population is at risk of hunger or experiences hunger ${ }^{(8)}$. Improving the quality of the diet is therefore challenging. Malnutrition during the school-aged years impacts negatively on the health, development and educational achievement of children, highlighting the importance of nutrition interventions targeting school-aged children in developing countries or countries in transition ${ }^{(9)}$.

Government schools in South Africa are grouped in quintiles according to the poverty level of the community where they are located. Schools in quintile 1 are the poorest and all the school funds come from the government; quintile 5 is the least poor and the bulk of the school funds are generated through school fees ${ }^{(10)}$. The National School Nutrition Program (NSNP), which targets schools in 
quintiles 1 to 3, forms part of the Integrated Food Security Strategy and 'seeks to contribute towards sustained provision of quality nutrition to learners, skills to establish food production initiatives in schools as well as promotion of healthy lifestyles in the school-communities threatened by poverty and hunger ${ }^{(11)}$. The NSNP consists of three components: (i) school feeding, with the aim to reduce short-term hunger by providing nutritious meals to learners on all school days, thus enhancing the child's learning capacity; (ii) nutrition education to improve nutritional knowledge as well as healthy eating and lifestyles among school communities; and (iii) sustainable food production initiatives to provide knowledge and transfer skills to schools and communities, thus improving teaching and learning and household food security ${ }^{(11)}$.

A significant number of South African children go to school either hungry ${ }^{(12)}$ or without having eaten breakfast ${ }^{(13)}$, which may have detrimental effects on their cognitive abilities and school performance ${ }^{(14)}$, hence the importance of school meals. Schools must serve meals early in the morning, at 10.00 hours ${ }^{(15)}$. Children are encouraged to carry a lunch box for later in the day. Learners can also buy food during school hours. Resource-rich schools usually have a designated tuck shop, while in the poorer schools foods are often sold through vendors. Schools can be a useful channel for promoting and instilling healthy eating habits in youth because of the large captive audience, the natural learning environment and the numerous opportunities for peer interaction. The school food environment, however, needs to be conducive to healthy eating habits.

The Department of Basic Education (DBE), having had full responsibility for the NSNP since 2004, requested the FAO to assist in strengthening the sustainable food production and nutrition education components of the NSNP. This included an assessment of knowledge, perceptions and practices on food production and nutrition of learners, educators and parents; food production in schools and utilisation of garden produce; school food vending and learners' lunch boxes. The aims of the part of that study reported in the current paper were to assess: (i) school feeding in terms of food items served and inclusion of fruit and vegetables in the school meal; (ii) school vending in terms of type of foods available to learners during school hours; (iii) lunch box of the learners in terms of type of foods brought from home to school; and (iv) nutrition education activities within the classroom. The assessment of agricultural knowledge, perceptions and practices of educators, learners and parents, and of food production practices in schools and utilisation of garden produce, is reported elsewhere ${ }^{(16)}$.

\section{Methods}

\section{Study population and design}

South Africa has a total population of 51.7 million people ${ }^{(17)}$. The country is divided into nine provinces, which are subdivided into fifty-three districts (forty-seven municipal and six metropolitan districts). The study included one district in each of the nine provinces. Regions included were: Port Elizabeth and Uitenhage in the Nelson Mandela Bay metropolitan district (total population: 1.1 million $^{(17)}$ ) in the Eastern Cape Province; Xhariep (total population: $146250^{(17)}$ ) in the Free State Province; Gauteng North in the City of Tshwane metropolitan district (total population: 2.9 million $^{(17)}$ ) in Gauteng Province; Ethekwini and Pinetown in the Ethekwini metropolitan district (total population: $3 \cdot 4$ million ${ }^{(17)}$ ) in KwaZulu-Natal Province; Sekhukhune (total population: $1 \cdot 1$ million $^{(17)}$ ) in Limpopo Province; Nkangala (total population: $1 \cdot 3$ million $^{(17)}$ ) in Mpumalanga Province; Dr Kenneth Kaunda (total population: $695933^{(17)}$ ) in North West Province; Siyanda (total population: $\left.236783^{(17)}\right)$ in Northern Cape Province; and West Coast (total population: $391766^{(17)}$ ) in the Western Cape Province. As the study was the baseline for a project on sustainable food production and practical food and nutrition education in schools, the selection of the regions was based on diverse agro-ecological characteristics which are likely to influence food production and availability of certain types of foods within that environment. Another factor that was taken into consideration was a mixture of urban, peri-urban, farm and rural schools.

A cross-sectional survey was done in ten quintile 1 to 3 primary schools per district that were purposely selected by the DBE. The total study sample therefore consisted of ninety schools. For each of the ninety selected schools, data were collected from various sources through a set of structured questionnaires. A summary of the participants and information collected is provided in Table 1. In some provinces the anticipated number of completed questionnaires was not reached, as some of the selected study participants were not available on the survey day(s).

Twenty-eight field workers (DBE officials) were trained in data collection during a $5 \mathrm{~d}$ training workshop, which included a $1 \mathrm{~d}$ test trial in five schools in the Pretoria area. Data were collected from March to October 2010. Schools were informed about the survey dates beforehand. Before going to a school, arrangements were made for completion of consent forms for the learners and for the school to invite the relevant respondents for interviews. Trained officials of the DBE checked the questionnaires for completeness and ensured that vernacular responses had been translated to English before sending the completed questionnaires to the Agricultural Research Council in Pretoria.

\section{Measuring tools}

The fifth draft of the 'National guidelines for the implementation, monitoring and reporting on the National School Nutrition Programme, (12), guidelines received from FAO and reports on previous evaluations of the Primary School Nutrition Programme ${ }^{(18-20)}$ were used as framework to develop the measuring tools. 
Table 1 Summary of respondents and information collected

\begin{tabular}{l} 
Source of information \\
\hline School principal ( $n$ 85) \\
Educator responsible for coordinating the \\
operational requirements of the school \\
feeding (school feeding coordinator) ( $n$ 77) \\
Food handlers ( $n 84$ ) (one randomly selected \\
food handler per school) \\
Grade $\mathrm{R}$ (reception year) to grade 7 educators \\
( $n 687$ ) (one randomly selected educator per \\
grade). Results showed that $22 \%$ were male \\
and $78 \%$ female; $47 \%$ were between 40 and \\
50 years old; $52 \%$ had been at the current \\
school for at least 10 years
\end{tabular}

Grade 5 to 7 learners ( $n$ 2547) (30 randomly selected learners in grades 5 to $7 ; 10$ per grade per school). Results showed that $49 \cdot 7 \%$ were boys and $50.3 \%$ girls

Parents ( $n$ 731) (the original plan of randomly selecting parents for grade 5 learners was abandoned as some of the parents were working during school hours and others, especially in farm schools, did not have transport to come to school; we settled for a convenience sample of 10 parents per school). Results showed that $14 \%$ were male and $86 \%$ female; mostly in the age-groups of $31-40$ years $(38 \%)$ and $41-50$ years $(27 \%)$

Weekly school menu $(n 75)$ and the meal served on the day of the survey

Tuck shops and food vendors either on or outside the school premises ( $n$ 74) (foods available to the learners from a spaza shop/café/shop outside the school premises, as well as foods sold by educators and fellow learners were excluded for logistical reasons)
Self-administered questionnaire

Interviewed by a field worker

Self-administered questionnaire

Completed questionnaire in small groups under guidance of a field worker

Interviewed by a field worker

By observation using a checklist

By observation using a checklist
Information provided

- School environment (drinking water, electricity, food garden)

- Nutrition policies

- Whether school meal, foods sold to learners and learners' lunch box were usually discussed by the School Governing Body

- Aspects related to the school meal and the food handlers

- Experience with preparing the school meal and training received

- Their interest and training received in nutrition

- Nutrition included in classroom teaching

- Their perceived role in nutrition education and promoting healthy eating among learners

- Whether school meal, foods sold to learners and learners' lunch box were usually discussed by Parent-Educator Association

- Perceived nutritional problems affecting the learners

- Whether breakfast was consumed and what foods were eaten

- Whether foods were brought to school and what food items were brought

- Whether foods were purchased during school hours and what food items were purchased

- Their thoughts on the school meal and foods sold to learners and how these could be improved 
were piloted in three provinces, one school per province. The schools were chosen in areas that were similar to the selected areas for the survey. The questionnaires were revised where needed.

\section{Data analysis}

Descriptive data analysis was done using the statistical software package IBM SPSS Statistics 18. Categorical data were expressed as frequencies and percentages. For the learners, information obtained through open-ended questions was discarded, as most of the answers either did not make sense or were illegible. Missing values were excluded during data analysis.

\section{Etbical considerations}

The study was conducted according to the guidelines laid down by the Declaration of Helsinki and all procedures involving human subjects were approved by the Ethics Committee of the Medical Research Council (EC09-015). Permission to do the study was obtained from the relevant senior managers in the provincial Departments of Education and school principals. Written informed consent was obtained from adult respondents (educators, parents involved in school feeding and garden). Written informed consent was obtained from the parents of the selected learners, and the learners gave written assent before completion of the questionnaire.

\section{Results}

The study sample included rural (49\%), peri-urban (19\%), urban (17\%) and farm (15\%) schools. A tap inside the school yard was the main source of drinking water in $81 \%$ of the schools and $98 \%$ of the schools had electricity. It was reported that $43 \%$ of the schools had a policy on nutrition, which was mostly based on the NSNP guidelines. According to the parents and educators, lack of money/poverty and high food prices were major constraints for healthy eating, affecting the nutrition of the learners (Table 2).

\section{Learners' breakfast and lunch box}

Twenty-two per cent of the learners had not eaten breakfast on the survey day. For those who had eaten breakfast, bread and porridge were the most popular foods, consumed mostly on their own, or with a protein source or fruit/vegetable. Only $24 \%$ of the learners carried a lunch box, mostly containing bread/sandwich (Table 3). Five per cent of the learners brought a drink to school on the survey day.

Thirteen per cent of the schools had a policy on the foods that learners bring to school, which focused mostly on healthy foods, limiting 'junk' food, and including fruit and a drink in the lunch box. The quality of the children's lunch box was usually discussed by the School Governing Body and during Parent-Educator Association meetings in $27 \%$ and $50 \%$ of the schools, respectively.

\section{School feeding programme}

The school meal was served to all learners in $77 \%$ of the schools and to only the neediest children in $21 \%$ of the schools. The school meal was served daily in $99 \%$ of the schools. The meal was prepared in proper (38\%) or makeshift (30\%) kitchens, a classroom or office (23\%), outside in the school yard $(8 \%)$ or in the community (1\%). In $84 \%$ of the schools, gas was the main fuel used for cooking. The remainder of the schools used wood as an open fire, either inside a room (7\%) or outside (5\%), and electricity (4\%). Food for the meal was obtained

Table 2 Factors affecting nutrition of learners, according to parents and educators, in a survey of ninety purposively selected poorly resourced schools (ten in each of the nine provinces) in South Africa, March-October 2010

\begin{tabular}{lrr}
\hline & $n$ & $\%$ \\
\hline Constraints for healthy eating, according to parents & & \\
Lack of money, poverty $(n$ 730) & 539 & 74 \\
Cost, high food prices $(n$ 730) & 498 & 68 \\
Certain foods are not available $(n$ 730) & 315 & 43 \\
Family doesn't like certain foods $(n$ 730) & 322 & 44 \\
Lack of knowledge $(n$ 730) & 226 & 31 \\
Myths $(n$ 730) & 134 & 18 \\
None $(n$ 730) & 33 & 4 \\
Nutritional problems affecting learners, according to educators $(n$ 687) & 160 & 23 \\
Problems related to the school meal & 124 & 18 \\
Poverty, unemployment & 59 & 8 \\
Lack of enough food, no breakfast, no lunch box & 174 & 25 \\
Unhealthy, too much junk food, too little variety & 63 & 10 \\
Too little fruit and/or vegetables, no vegetable garden at home & 20 & 3 \\
Malnutrition & 21 & 3 \\
Lack of knowledge (parents/children) & 13 & 2 \\
Poor hygiene & 22 & 3 \\
None & 31 & 4 \\
Don't know & & 2 \\
\hline
\end{tabular}


Table 3 Breakfast eaten by learners and contents of their lunch box in a survey of ninety purposively selected poorly resourced schools (ten in each of the nine provinces) in South Africa, March-October 2010

\begin{tabular}{lrr}
\hline & $n$ & $\%$ \\
\hline Foods eaten before coming to school ( $n$ 2547) & & \\
Bread (on its own) & 863 & 34 \\
Bread plus meat, fish, polony, egg, cheese, cereal, fruit, vegetable & 160 & 6 \\
Porridge (on its own) & 527 & 21 \\
Porridge plus meat/fish, chicken, egg, beans, vegetable, fruit & 98 & 4 \\
Breakfast cereal, Morvite*, oats & 214 & 8 \\
Fruit (on its own) & 12 & 1 \\
Cooked food, rice, meat, fish, chicken, eggs, beans, vegetable, potato & 48 & 2 \\
Muffin, vetkoekt, dumpling, cake, biscuits, chips, sweets & 27 & 1 \\
Illegible; not specified; missing & 43 & 2 \\
Did not eat anything & 555 & 22 \\
Foods brought from home ( $n$ 2547) & 507 & 20 \\
Bread, sandwich & 21 & 1 \\
Fruit, yoghurt & 17 & 1 \\
Cake, biscuits, sweets, chips & 49 & 10 \\
Cooked food, meat, egg, fish, polony, porridge, vetkoek & 1943 & 1 \\
Variety of other food items & & 76 \\
No lunch box & & 2 \\
\hline
\end{tabular}

*Vitamin- and mineral-enriched sorghum-based cereal.

tTraditionally made with yeast bread dough that is shaped into balls and deep fried in oil.

Table 4 Information on the school meal, food handlers' and parents' perception of the school meal, in a survey of ninety purposively selected poorly resourced schools (ten in each of the nine provinces) in South Africa, March-October 2010

\begin{tabular}{|c|c|c|}
\hline & $n$ & $\%$ \\
\hline \multicolumn{3}{|l|}{ Training received by food handlers* } \\
\hline Basic hygiene in preparation of food $(n 84)$ & 73 & 87 \\
\hline Preparation of food for school meal ( $n$ 84) & 54 & 64 \\
\hline Mixing of food items ( $n$ 84) & 58 & 69 \\
\hline Amount of food to be served per child ( $n$ 84) & 62 & 74 \\
\hline Gas safety $(n 84)$ & 52 & 68 \\
\hline Food storage ( $n 84)$ & 30 & 83 \\
\hline \multicolumn{3}{|l|}{ Problems experienced with school meal ${ }^{*}(n 84)$} \\
\hline Lack of storage space & 27 & 32 \\
\hline Lack of water & 23 & 27 \\
\hline Lack of cooking utensils & 15 & 18 \\
\hline Lack of fuel to cook food & 14 & 17 \\
\hline Insufficient labour and/or time to prepare and serve the food & 20 & 24 \\
\hline Food supply is too little and/or of poor quality & 25 & 30 \\
\hline Lack of knowledge on meal preparation & 12 & 14 \\
\hline No support from teachers & 18 & 21 \\
\hline \multicolumn{3}{|l|}{ Parents' feelings towards school meal ( $n$ 731) } \\
\hline No problem with school meal & 16 & 2 \\
\hline Positive (happy, satisfied, good) & 510 & 70 \\
\hline Negative (not happy) & 153 & 21 \\
\hline Illegible; don’t know; irrelevant answer & 52 & 7 \\
\hline \multicolumn{3}{|l|}{ Parents' thoughts on how the school meal could be improved ( $n 731)$} \\
\hline More fruit and/or vegetables/school should plant vegetables & 293 & 40 \\
\hline Change menu/more variety/no soya & 147 & 20 \\
\hline Healthier/better quality food & 45 & 6 \\
\hline Serve more food $/$ meals & 40 & 5 \\
\hline Improve preparation/more tasty/train cook & 40 & 5 \\
\hline Nothing/no problem & 50 & 7 \\
\hline Variety of answers; illegible; missing; don't know & 116 & 16 \\
\hline
\end{tabular}

*Information provided by the food handler.

mostly from the suppliers (95\% of schools), and to a lesser extent the school's food garden (43\%) and food locally grown in the community (9\%).

More than $60 \%$ of the food handlers had received training in the individual topics listed. Problems experienced with the school meal included lack of storage space (32\%), lack of water (27\%) and insufficient amount and/or poor quality of the food supply (30\%; Table 4). Most of the schools had water and soap available for the food handlers to wash their hands. 


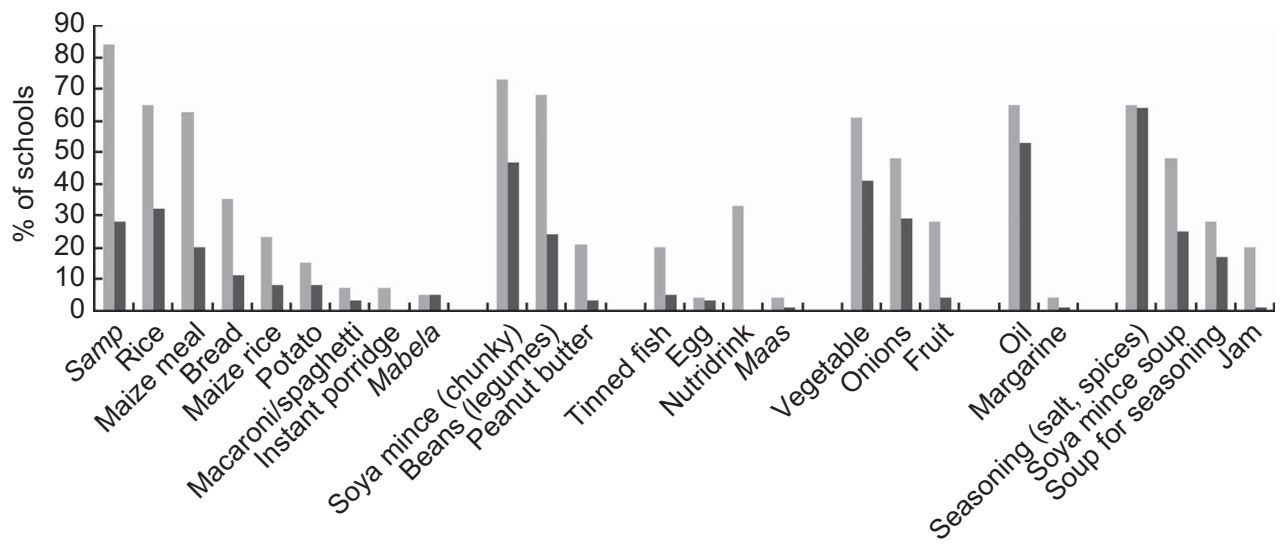

Fig. 1 Foods on the school menu $(\square)$ and served on the day of the survey $(\square)$ among ninety purposively selected poorly resourced schools (ten in each of the nine provinces) in South Africa, March-October 2010 (samp= dehulled dried broken maize kernels; Nutridrink = fortified drink; maize rice = also known as mealie rice, finely cut maize in which the bran and germ has been partly removed; mabela = porridge prepared with ground sorghum; maas = fermented milk)

The school meal was assessed particularly for inclusion of vegetables and fruit. Foods on the school menu and those served on the survey day are indicated in Fig. 1. Samp (84\%), soya mince (73\%), beans (68\%), oil (65\%), seasoning (65\%), rice (65\%), maize meal (63\%) and vegetables $(61 \%)$ were on the menu in at least $60 \%$ of the schools. Vegetables, mostly cabbage, and to a lesser extent carrot and butternut squash, were on the menu in $61 \%$ of the schools, but were served in only $41 \%$ of the schools on the survey day. Fruit, mostly apple and banana, were on the menu in $28 \%$ of the schools, but were served in only $4 \%$ of the schools on the survey day.

Seventy per cent of the parents were positive towards the school meal, of whom $15 \%$ felt positive because many of the children come from poor households. Twenty-one per cent of the parents were negative towards the school meal, mostly because the menu lacked variety and they were generally not happy with the foods on the menu. Six per cent of the parents were very specific in terms of the unacceptability of soya on the menu, and parents in six of the nine provinces suggested that soya be removed from the menu. Parents thought that the school meal could be improved by adding fruit and/or vegetables and changing the menu (Table 4). The quality of the school meal was usually discussed by the School Governing Body and during Parent-Educator Association meetings in 85\% and $59 \%$ of the schools, respectively.

\section{School vending}

Of the seventy-four schools for which the school vending checklist was completed, eleven did not sell any food to learners during school hours on the survey day. Data on foods sold were obtained from sixty-three schools, of which $29 \%$ sold food through the school's tuck shop (a building/structure on the school premises where food is sold), $49 \%$ through food vendors on the school premises and $22 \%$ through food vendors outside the school premises. A variety of foods were sold, including mostly unhealthy options such as chips/niknaks, sweets/ chocolates and biscuits. Peanuts were classified as a snack food, because of the high salt content. Fruit was sold in $30 \%$ of the sixty-three schools for which data were obtained (Fig. 2).

Nineteen per cent of the schools had a policy on the foods sold to the learners, which focused mostly on clean and healthy foods. One of the schools reported that it does not allow vendors on the school premises (Table 5). The quality of food sold during school hours was usually discussed by the School Governing Body and during Parent-Educator Association meetings in $45 \%$ and $44 \%$ of the schools, respectively.

Just over half $(57 \%)$ of the learners brought money to school on the survey day (median of R2; approx \$US 0.25). Twenty-four per cent of the parents did not know what type of food their children buy at school. Parents advised their children to buy fruit (37\%) and healthy foods (23\%). Thirty-two per cent of the parents thought that the foods sold to the learners were unhealthy or could be healthier. According to the parents, foods sold to learners can be improved by selling fruit (24\%) and healthier food options (17\%). Parents had some concerns regarding the food stall itself, stating that a shelter should be built for the vendors and that the food should be protected from the sun and be clean (Table 5).

\section{Classroom activities}

Approximately $15 \%$ of the educators had received training in nutrition and nutrition education, and $83 \%$ showed an interest in nutrition. Nearly all the educators (99\%) agreed that they, as educators, need to promote good health and nutrition among learners, mostly through teaching the learners on health and nutrition (46\%), encouraging the learners to eat healthily (15\%) and by setting an example (11\%; Table 6). Eighty-one per cent of 


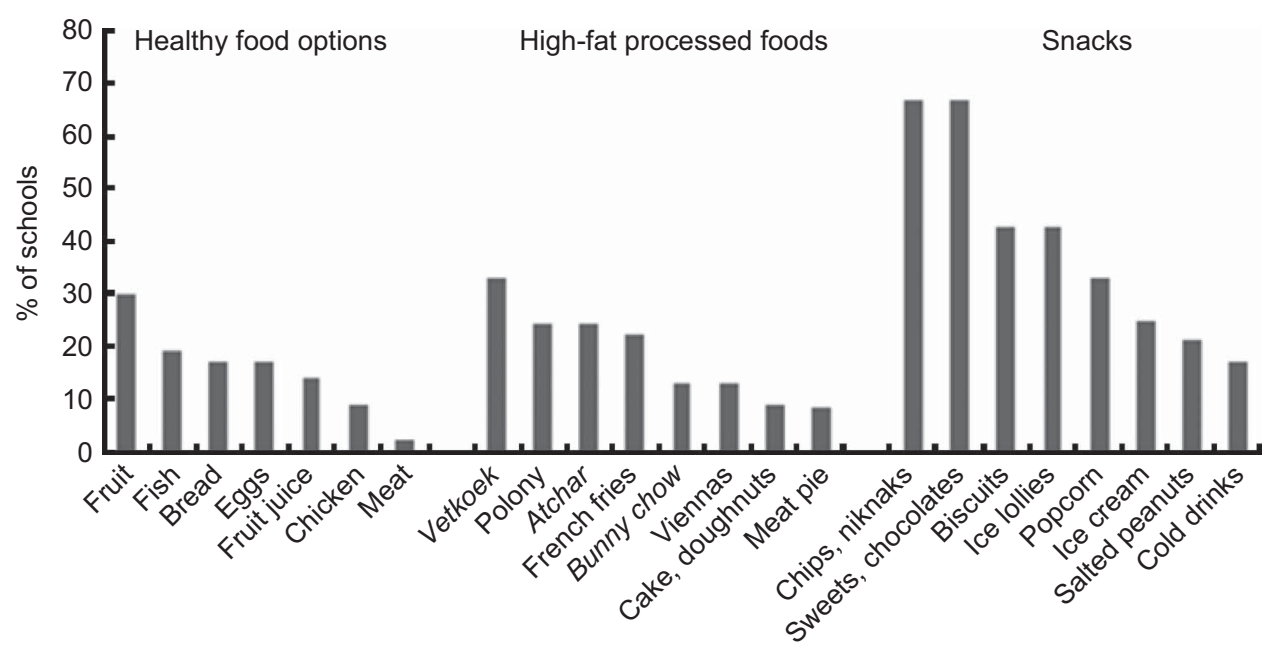

Fig. 2 Foods sold at the tuck shop and by food vendors on the day of the survey among ninety purposively selected poorly resourced schools (ten in each of the nine provinces) in South Africa, March-October 2010 (vetkoek= traditionally made with yeast bread dough that is shaped into balls and deep fried in oil; atchar= relish made with unripe green mangoes and chillies and blended with oil; bunny chow = quarter of a loaf of white bread that has been hollowed out and filled with curried meat)

Table 5 Information related to foods sold at school in a survey of ninety purposively selected poorly resourced schools (ten in each of the nine provinces) in South Africa, March-October 2010

\begin{tabular}{|c|c|c|}
\hline & $n$ & $\%$ \\
\hline \multicolumn{3}{|l|}{ Parents' feelings towards food being sold ( $n$ 731) } \\
\hline It is unhealthy/must be healthy & 238 & 32 \\
\hline Not happy/not good/don't want them & 128 & 18 \\
\hline Cleanliness is a problem & 20 & 3 \\
\hline Good/happy/okay & 113 & 15 \\
\hline No problem with food sold & 47 & 6 \\
\hline No tuck shop or vendors at child's school & 48 & 7 \\
\hline Variety of answers; illegible; don't know & 137 & 19 \\
\hline \multicolumn{3}{|l|}{ Parents' thoughts on ways to improve food being sold $(n 731)$} \\
\hline Sell fruit & 179 & 24 \\
\hline Sell healthy food/no unhealthy food & 127 & 17 \\
\hline $\begin{array}{l}\text { Build shelter for vendors; stall must be clean; food must be covered and not exposed to sun; train and monitor } \\
\text { the food vendors; need to be controlled }\end{array}$ & 137 & 19 \\
\hline Ban them & 20 & 3 \\
\hline Nothing needs to change & 20 & 3 \\
\hline No tuck shop or vendors at child's school & 48 & 7 \\
\hline Variety of answers; illegible; don’t know & 200 & 27 \\
\hline \multicolumn{3}{|l|}{ Parents' advice to children on which foods to buy (for those whose children take money to school) ( $n$ 574) } \\
\hline Buy fruit & 215 & 37 \\
\hline Buy healthy foods & 132 & 23 \\
\hline Do not buy unhealthy foods & 134 & 23 \\
\hline No advice/their choice & 59 & 10 \\
\hline Variety of answers; illegible; don't know & 34 & 6 \\
\hline \multicolumn{3}{|l|}{ School has rules on the following* $(n 85)$} \\
\hline Cleanliness of 'food stall' & 38 & 45 \\
\hline Food safety of foods sold & 32 & 38 \\
\hline Type of foods sold by food vendors & 31 & 36 \\
\hline Storage of foods sold & 30 & 35 \\
\hline Preparation of foods sold & 26 & 31 \\
\hline Source of foods sold & 23 & 27 \\
\hline
\end{tabular}

${ }^{*}$ According to the school principal.

the educators taught nutrition as part of school subjects, particularly life orientation (56\%), reading (25\%) and natural sciences $(21 \%)$. The school meal, foods sold in and around the school, and the learners' lunch box were discussed in the classroom by approximately $50 \%$ or less of the educators (Table 6).

\section{Discussion}

The current study provided information on the school food environment that should be considered in the school feeding and nutrition education components of the NSNP. Areas of concern that were identified are learners not 
Table 6 Classroom activities related to nutrition, according to educators, in a survey of ninety purposively selected poorly resourced schools (ten in each of the nine provinces) in South Africa, March-October 2010

\begin{tabular}{lrr}
\hline & $n$ & $\%$ \\
\hline Activities that are part of the classroom programme & & \\
Discuss the school meal ( $n$ 671) & 374 & 56 \\
Discuss the food sold in or around the school $(n 667)$ & 377 & 56 \\
Describe the food sold in or around the school $(n 667)$ & 341 & 51 \\
Evaluate the school meal $(n 667)$ & 317 & 48 \\
Describe the school meal $(n 669)$ & 298 & 47 \\
Evaluate the food sold in/around the school $(n$ 664) & 291 & 45 \\
Discuss the learners' lunch box $(n$ 671) & 244 & 43 \\
Describe the learners' lunch box $(n$ 666) & 231 & 37 \\
Evaluate the learners' lunch box $(n$ 666) & 318 \\
Educators' perception on their role in promoting nutrition among learners $(n$ 687) & 100 \\
Teach on health and nutrition & 76 & 35 \\
Encourage and motivate learners to eat healthy & 41 \\
Promote healthy eating/set an example & 25 & 15 \\
Teach learners to wash hands before eating & 127 \\
Encourage to have vegetable gardens at home & 6 \\
Irrelevant answer; illegible; missing; don't know & 4 \\
\hline
\end{tabular}

eating breakfast, low content of vegetables and fruit in the school meal, unhealthy food items sold through tuck shops and vendors, and learners not carrying a lunch box. The study included schools in quintiles 1 to 3, as these schools are the focus of the NSNP, and is therefore focused towards poorly resourced schools. The study included ninety schools that were purposively selected to cover a range of agro-ecological characteristics in all nine provinces of South Africa.

A large proportion of the schools did not comply with the mandate of serving vegetables and/or fruit every day, as stipulated in the 2011-12 Conditional Grant Framework $^{(15)}$. Vegetables and fruit are bulky and perishable, and quality and appearance can be a barrier for consumption ${ }^{(21)}$. Schools need the capacity to appropriately store vegetables and fruit, which could be problematic as many schools lacked storage space. Access to fresh vegetables and fruit can be increased through increased local production, either in the school garden or in the community, and by linking the school to local farmers (www.farmtoschool.org). The agricultural component of the study showed that learners and educators were positive about food gardening ${ }^{(16)}$. School gardens can also be used as a platform for learning about gardening and healthy eating ${ }^{(22)}$. A horticulture manual was developed to strengthen school gardening activities within the $\operatorname{NSNP}^{(23)}$.

The number of children carrying a lunch box was low and, similar to the results of a previous localised study ${ }^{(24)}$, the contents consisted mostly of bread. Previous studies have shown that learners who attended schools of high socio-economic status were twice as likely to bring food to school $^{(13)}$ and that learners from rural and disadvantaged settings were less likely to bring a lunch box to school because of a lack of food available at home ${ }^{(24)}$.

Learners relied more on vendors and tuck shops for food, than on a lunch box. Foods sold to the learners were mostly unhealthy options, which is in line with previous studies in specific settings ${ }^{(13,24,25)}$. Parents advised their children to buy healthier food options, but this could only be achieved if these were available and affordable. There are several barriers for selling healthier foods. Tuck shop managers in quintile 5 schools (least poor schools) in a city were shown to be reluctant to stock fruit because when they did stock it, it stayed on the shelf and decayed ${ }^{(25)}$. Other barriers include children's preference for unhealthy foods ${ }^{(21,26)}$, a fear of losing income through selling these food items ${ }^{(27)}$ and the higher cost of healthier foods ${ }^{(21,28)}$. Against the backdrop of overweight and obesity among schoolchildren in South Africa ${ }^{(2,3)}$, regulation of foods sold to children during school hours and programmes advocating healthy food options should be encouraged. Furthermore, the concerns of the parents in terms of the stall itself should be addressed, i.e. providing a shelter for the vendors, ensuring that the food is protected from the sun and the dust, and that the stall is clean.

Moore and Tapper ${ }^{(29)}$ showed that fruit tuck shops on their own did not change children's snacking behaviour, but those combined with applicable school policies on the types of foods children were allowed to bring to school had a greater impact. Also, children's attitudes, nutrition knowledge, food preference and consumption patterns in terms of vegetables and fruit were shown to be positively affected through school gardens as a component of nutrition education ${ }^{(30,31)}$. Promoting healthy eating through a comprehensive approach that includes the classroom curriculum, policy and environmental changes, and support of parents and the community, may create a demand for healthier food options to be sold.

A small number of educators had received training in nutrition and nutrition education, but nearly all educators agreed that they, as educators, need to promote good 
health and nutrition among learners. Educators should be trained in nutrition, preferably as part of their formal training. The nutrition education component of the NSNP was recently strengthened by making available an educators' manual on nutrition education ${ }^{(32)}$, based on the South African food-based dietary guidelines. Educators should now be provided with creative nutrition education and good classroom materials that include teaching guidelines to ensure that this information is integrated into the classroom curriculum. This will require collaboration between the NSNP and the school curriculum authorities. To ensure that learners are able to incorporate the food-based dietary guidelines into their daily lives, nutrition education in schools should be extended to include the parents. The importance of targeting the family environment for the promotion of healthy eating behaviours among children and adolescents was highlighted by Pearson and co-workers ${ }^{(33)}$. Lessons alone, however, will not necessarily result in behaviour change ${ }^{(34)}$. Poverty, cultural practices and lack of influence over food choices may limit learners' ability to change dietary practices ${ }^{(35)}$. Sponsored signage boards on school premises displaying unhealthy foods ${ }^{(27)}$ may also be a barrier for instilling healthy dietary practices among schoolchildren.

Poverty was perceived as a major challenge affecting healthy eating among learners. Healthier food choices are, in general, more expensive than commonly consumed foods, and it has been argued that a healthy diet is unaffordable for the large majority of South African households ${ }^{(28)}$. Cost is a major constraint prohibiting frequent consumption of vegetables and fruit ${ }^{(36,37)}$ and households are therefore not able to purchase these regularly. Through nutrition education and food production initiatives within the NSNP in schools, households can be encouraged to plant a variety of vegetables and fruit for home consumption. Multi-component interventions were shown to be effective in promoting a healthy diet in schoolchildren in, for example, Europe ${ }^{(38)}$.

Based on the survey results, several recommendations can be made to create, from a nutritional perspective, a healthier food environment at schools. An integrated approach considering socio-economic aspects is needed. Vegetables and fruit should be served in the school meal more often, and schools should have the means to do so. Foods sold to learners through vendors (either on or outside the school premises) and tuck shops should be regulated and children should be encouraged to carry a healthy lunch box. Teaching guidelines are needed to integrate nutrition education into the classroom curriculum and the nutrition education should be extended to include the parents. Horticulture and nutrition education manuals were made available to the schools and it is suggested that in a year or two, a follow-up survey is conducted to assess the use of these manuals within the NSNP in schools.

\section{Acknowledgements}

Sources of funding: The study was funded and technically supported by the FAO. Conflicts of interest: The authors have no conflicts of interest. Authors' contributions: M.F. and S.L. designed the study, developed the questionnaires and trained the field workers; M.F. analysed the data and wrote the manuscript; M.M. and T.M. provided technical input and took responsibility for the execution of the field work; E.M. provided technical input; S.L. and E.M. contributed towards writing of the manuscript. Acknowledgements: The authors thank the nine provincial Departments of Education and District Offices which provided access to the schools to collect data; the officials who conducted the field work; the schools and community members (principals, educators, learners, volunteer food handlers, school gardeners/general workers and parents) who participated in the study; officials from the National and Provincial Departments of Education who assisted with validation and translation of questionnaires; Dr Carl Lombard, statistician in the Biostatistics Unit of the Medical Research Council, for assistance in determining sample sizes; and Mrs Lee-Ann Human of the Nutritional Intervention Research Unit of the Medical Research Council for data management.

\section{References}

1. Kruger HS, Steyn NP, Swart EC et al. (2011) Overweight among children decreased, but obesity prevalence remained high among women in South Africa, 1999-2005. Public Health Nutr 15, 594-599.

2. Kimani-Murage EW, Kahn K, Pettifor JM et al. (2010) The prevalence of stunting, overweight and obesity, and metabolic disease risk in rural South African children. BMC Public Health 10, 158.

3. Reddy SP, James S, Sewpaul R et al. (2010) Umthente Ublaba Usamila - The 2nd South African Youth Risk Behaviour Survey 2008. Cape Town: South African Medical Research Council; available at http://www.mrc.ac.za/health promotion/yrbs_2008_final_report.pdf

4. Department of Health, South African Medical Research Council \& ORC Marco (2007) South Africa Demographic and Health Survey 2003. http://www.measuredhs.com/ pubs/pdf/FR206/FR206.pdf (accessed June 2010).

5. Labadarios D, Steyn N, Maunder E et al. (2000) National Food Consumption Survey of 1-9 Year Old Children in South Africa, 1999. Pretoria: Department of Health, Directorate of Nutrition.

6. Labadarios D, Steyn NP \& Nel J (2011) How diverse is the diet of adult South Africans? Nutr J 10, 33.

7. Steyn NP, Nel JH, Nantel G et al. (2006) Food variety and dietary diversity scores in children: are they good indicators of dietary adequacy? Public Health Nutr 9, 644-650.

8. Labadarios D, Mchiza ZJR, Steyn NP et al. (2011) Food security in South Africa: a review of national surveys. Bull World Health Organ 89, 891-899.

9. Best C, Neufingerl N, van Geel L et al. (2010) The nutritional status of school-aged children: why should we care? Food Nutr Bull 31, 400-417.

10. Acts Online (2009) South African Schools Act, 1996, (Act No 84 of 1996). Amended National Norms and Standards 
for School Funding. 5. The School Allocation. http:// www.acts.co.za/ed_sasa/amend_norms_5_the_school_ allocation.htm (accessed October 2012).

11. Department of Education (2008) National Guidelines for the Implementation, Monitoring and Reporting on the National School Nutrition Programme. Draft 5. Pretoria: South African Department of Education.

12. Public Service Commission (2008) Report on the Evaluation of the National School Nutrition Programme (NSNP). Pretoria: The Public Service Commission; available at http:// www.info.gov.za/view/DownloadFileAction?id $=88572$

13. Temple NJ, Steyn NP, Myburgh NG et al. (2006) Food items consumed by students attending schools in different socioeconomic areas in Cape Town, South Africa. Nutrition 22, 252-258.

14. Grantham-McGregor S (2005) Can the provision of breakfast benefit school performance. Food Nutr Bull 26, Suppl. 2, S144-S158.

15. Department of Basic Education (date not known) 2011-12 Conditional Grant Framework. National School Nutrition Programme Grant. Pretoria: South African Department of Basic Education.

16. Laurie SM, Faber M, Malebana ME et al. (2013) Results from a survey on school-based food gardens in South Africa: perceptions of teachers and learners. Proceedings of the 2nd All Africa Horticulture Congress. Acta Horticulturae (In the Press).

17. Statistic South Africa (date not known) Census 2011 Municipal fact sheet. http://www.statssa.gov.za/Census2011/Products/ Census_2011_Municipal_fact_sheet.pdf (accessed March 2013).

18. McCoy D, Barron P \& Wigton A (editors) (1997) An Evaluation of South Africa's Primary School Nutrition Programme. Report prepared on behalf of the Child Health Unit of the University of Cape Town for the Health Systems Trust. Durban: Health Systems Trust; available at http:// www.hst.org.za/sites/default/files/psnp.pdf

19. Louw R, Bekker E \& Wentzel-Viljoen E (2001) External Evaluation of Certain Aspects of Primary School Feeding. Report produced for the South African Department of Health. Pretoria: South African Department of Health.

20. Wentzel-Viljoen E, Swart EC, Vorster HH et al. (2000) Evaluation of the Primary School Nutrition Programme (PSNP) in the North West Province. Final report to the Department of the Premier, North West Province. Mmabatho: North West Provincial Government.

21. Krølner R, Rasmussen M, Brug J et al. (2011) Determinants of fruit and vegetable consumption among children and adolescents: a review of the literature. Part II: qualitative studies. Int J Behav Nutr Phys Act 8, 112.

22. Food and Agriculture Organization of the United Nations (2010) Setting Up and Running a School Garden. Teaching Toolkit. Rome: FAO.

23. Department of Basic Education (2011) Horticulture Manual for Schools: A Guide to Establish and Sustain Food Gardens. Pretoria: National School Nutrition Programme, South African Department of Basic Education.

24. Abrahams Z, de Villiers A, Steyn NP et al. (2011) What's in the lunchbox? Dietary behaviour of learners from disadvantaged schools in the Western Cape, South Africa. Public Health Nutr 14, 1752-1758.

25. Wiles NL, Green JM \& Veldman FJ (2011) The variety, popularity and nutritional quality of tuck shop items available for sale to primary school learners in Pietermaritzburg, South Africa. S Afr J Clin Nutr 24, 129-135.

26. Marracini T, Meltzer S, Bourne L et al. (2012) A qualitative evaluation of exposure to and perceptions of the Woolworths Healthy Tuck Shop Guide in Cape Town, South Africa. Child Obes 8, 369-377.

27. De Villiers A, Steyn NP, Draper CE et al. (2012) 'HealthKick': formative assessment of the health environment in low-resource primary schools in the Western Cape Province of South Africa. BMC Public Health 12, 794.

28. Temple NJ, Steyn NP, Fourie J et al. (2011) Price and availability of healthy foods: a study in rural South Africa. Nutrition 27, 55-58.

29. Moore L \& Tapper K (2008) The impact of school fruit tuck shops and school food policies on children's fruit consumption: a cluster randomised trial of schools in deprived areas. J Epidemiol Community Health 62, 926-931.

30. Somerset S \& Markwell K (2009) Impact of a school food garden on attitudes and identification skills regarding vegetables and fruit: a 12-month intervention trial. Public Health Nutr 12, 214-221.

31. Parmer SM, Salisbury-Glennon J, Shannon D et al. (2009) School gardens: an experiential learning approach for a Nutrition Education Program to increase fruit and vegetable knowledge, preference, and consumption among second-grade students. J Nutr Educ Behav 41, 212-217.

32. Department of Basic Education (2010) Nutrition Educators Manual Volume 1: Educators. Pretoria: South African Department of Basic Education.

33. Pearson N, Biddle SJH \& Gorely T (2008) Family correlates of fruit and vegetable consumption in children and adolescents: a systematic review. Public Health Nutr 12, 267-283.

34. Ransley JK, Taylor EF, Radwan Y et al. (2010) Does nutrition education in primary schools make a difference to children's fruit and vegetable consumption? Public Health Nutr 13, 1898-1904.

35. Oosthuizen D, Oldewage-Theron WH \& Napier C (2011) The impact of a nutrition programme on the dietary intake of primary school children. S Afr J Clin Nutr 24, 75-81.

36. Love P, Maunder E, Green M et al. (2001) South African food-based dietary guidelines. Testing of the preliminary guidelines among women in KwaZulu-Natal and the Western Cape. S Afr J Clin Nutr 14, 9-19.

37. Faber M, Laubscher R \& Laurie S (2013) Availability of, access to, and consumption of fruits and vegetables in a peri-urban area in KwaZulu-Natal, South Africa. Matern Child Nutr 9, 409-424.

38. Van Cauwenberghe E, Maes L, Spittaels H et al. (2010) Effectiveness of school-based interventions in Europe to promote healthy nutrition in children and adolescents: systematic review of published and 'grey' literature. $\mathrm{BrJ}$ Nutr 103, 781-797. 